Article

\title{
Is Orius sauteri Poppius a Promising Biological Control Agent for Walnut Aphids? An Assessment from the Laboratory to Field
}

\author{
Ting Wang ${ }^{1,2}$, Ping Zhang ${ }^{2}$, Chenyang Ma ${ }^{2}$, Muhammad Yasir Ali ${ }^{1}$, Guizhen Gao ${ }^{3}$, Zhaozhi Lu ${ }^{1, *}$ \\ and Myron P. Zalucki ${ }^{4}$
}

check for

updates

Citation: Wang, T.; Zhang, P.; Ma, C.; Yasir Ali, M.; Gao, G.; Lu, Z.; Zalucki, M.P. Is Orius sauteri Poppius a Promising Biological Control Agent for Walnut Aphids? An Assessment from the Laboratory to Field. Insects 2021, 12, 25. https://doi.org/ $10.3390 /$ insects 12010025

Received: 17 November 2020 Accepted: 29 December 2020 Published: 4 January 2021

Publisher's Note: MDPI stays neutral with regard to jurisdictional clai$\mathrm{ms}$ in published maps and institutional affiliations.

Copyright: (C) 2021 by the authors. Licensee MDPI, Basel, Switzerland. This article is an open access article distributed under the terms and conditions of the Creative Commons Attribution (CC BY) license (https:// creativecommons.org/licenses/by/ $4.0 /)$.
1 Laboratory of Insect Ecology and Molecular Biology, College of Plant Health and Medicine of Qingdao Agriculture University, Qingdao 266109, China; liuxiaoxian18@mails.ucas.ac.cn (T.W.); zhaozhi@ms.xjb.ac.cn (M.Y.A.)

2 Xinjiang Institute of Ecology and Geography, Chinese Academy of Sciences, Urumqi 830011, China; zhangping16@mails.ucas.ac.cn (P.Z.); machenyang19@mails.ucas.ac.cn (C.M.)

3 College of Forestry and Horticulture, Xinjiang Agricultural University, Urumqi 830052, China; sunjing@xjau.edu.cn

4 School of Biological Sciences, The University of Queensland, Brisbane 4072, Australia; m.zalucki@uq.edu.au

* Correspondence: 201901166@qau.edu.cn; Tel.: +86-532-58957787

Simple Summary: Walnut aphids are major pests of walnut orchards with few commercially available natural enemies except parasitoids. The predatory bug (Orius sauteri) was assessed as a potential biological control agent against two walnut aphid species. This bug has a strong capacity for consuming both aphid species. Biocontrol efficacy of $O$. sauteri for each species was high (more than $70 \%$ ), but declined about $20 \%$ when both aphid species present on the same leaf together. This might be due to the competition among two species of aphids tested. Three statistical approaches were employed to show that $O$. sauteri is a promising biocontrol agent. The commercial release of $O$. sauteri should be considered for the coexisting aphids in walnut orchards to promote economic and environmental benefits.

Abstract: Walnut aphids are major pests of walnut production with few commercially available natural enemies. We conducted laboratory and field experiments to evaluate the potential of Orius sauteri Poppius (Anthocoridae), a predatory bug, as a biological control agent against two walnut aphid species: the dusky-veined aphid (Panaphis juglandis Goeze) and the walnut aphid (Chromaphis juglandicola Kaltenbach). Both species co-occur on walnut trees; P. juglandis is distributed on the upper surface (adaxial) of leaves while C. juglandicola is found on the lower surface (abaxial) of leaves. Based on functional response experiments, O sauteri had a strong capacity for consuming both aphid species. Biocontrol efficacy of $O$. sauteri for each species in the laboratory and field experiments was high, $77 \%$ for $P$. juglandis and $80 \%$ for C. juglandicola, regardless if one or two predators being present. However, biocontrol efficacy declined $15-25 \%$ for $C$. juglandicola and $20-50 \%$ for $P$. juglandis when both aphid species were present on the same leaf. The efficacy of $O$. sauteri under (semi)-field conditions gave similar findings based on the percentage reduction of aphids and change in population growth rates of aphids. The reduced biocontrol efficacy of the predatory bug against mixed species populations of aphids can be explained by competition between the aphid species and differences in their preferred location on leaves. Our experiments showed that $O$. sauteri is a promising biocontrol agent, but biocontrol efficacy may decline when both aphid species are present on walnut trees. This should be considered in the commercial release of $O$. sauteri in walnut orchards to promote economic and environmental benefits of walnuts production.

Keywords: biological control efficiency; Chromaphis juglandicola Kaltenbach; dusky-veined aphid; Panaphis juglandis Goeze; walnut aphid 


\section{Introduction}

The biological control of pests by their natural enemies is a crucial ecosystem service that substantially contributes to protecting the environment as well as maintaining biodiversity [1]. Natural enemies are commercially available for the protection of crops and trees [2]. Biological control has been widely employed as a sustainable component of integrated pest management worldwide with economic, environmental, and social benefits [3], with the value of biological control to the entire biosphere estimated at $\$ 417$ billion per year [4]. More than 150 species of natural enemies are commercially available to be used in agricultural production [5]. The efficacy of new biocontrol agents needs to be assessed before they can be considered as part of an integrated pest management program and commercially produced.

Walnut (Juglans regia L.) cultivation is widespread around the world [6], but the walnut aphids, Chromaphis juglandicola (Kaltenbach), and dusky-veined aphid Panaphis juglandis (Goeze) have become major pests in walnut orchards where they reduce the quality and yield of nuts [7,8]. In recent years, these increasingly prevalent aphids have resulted in huge economic losses due to the reduction in tree vigor and nut size, yield, and quality $[9,10]$. The two aphid species colonize walnut trees at the same time with the relatively large aphid P. juglandis (adults 3.5-4.3 $\mathrm{mm}$ in length) feeding on the upper surface of leaves (adaxial) and the small aphid, C. jugandicola $(1.2-2.3 \mathrm{~mm}$ ) feeding on the lower surface of leaves (abaxial) [11]. Effective biological control of walnut aphids began in 1969 when the parasitoid wasp Trioxys pallidus Haliday was imported from Iran to California to control C. juglandicola [12]. But the competing primary and hyperparasitoids reduced the biocontrol efficacy of the parasitoids on aphids in the field. [13].

The anthocorid bug genus Orius Wolff has been regarded as a promising biological control agent for agricultural pests such as thrips, aphids, and mites [14-16]. Orius sauteri Poppius is a mass-produced biological control agent [17-20], which can be used to suppress many aphid species [18]. However, the efficacy of $O$. sauteri has not been assessed specifically for the control of aphids in walnut orchards. Here, we evaluate O. sauteri as a biological control agent against the two aphid species that are major pests of walnut trees: C. juglandicola and P. juglandis. This assessment will assist the integrated pest management program for walnut orchards.

\section{Materials and Methods}

\subsection{Insect Collection}

The laboratory experiments were carried out during 2019 and 2020; P. juglandis and C. juglandicola were collected from walnut orchards located in Yili $\left(43^{\circ} 25^{\prime} \mathrm{N}, 082^{\circ} 82^{\prime} \mathrm{E}\right)$, China. The collected aphids were cultured on three-year-old walnut saplings for three generations under controlled conditions of $25 \pm 2{ }^{\circ} \mathrm{C}$ temperature, $75-80 \%$ relative humidity, and $14 \mathrm{~L}: 10 \mathrm{D}(\mathrm{h})$ photoperiod. Adults of $O$. sauteri were purchased from a commercial supplier (Shandong Lubao Technology Development, www.saas-birc.com). The sexes of O. sauteri bugs used in experiments were not identified.

\subsection{Laboratory Experiments}

2.2.1. The Functional Response of Predatory O. sauteri Bugs to Increasing Density of P. juglandis and C. juglandicola Aphids

The experiments were conducted in Petri dishes $(9 \mathrm{~cm}$ in diameter) with a fresh walnut tree leaf cut to the size of the Petri dish, and moistened filter paper placed under the leaf. Individual $O$. sauteri adults were starved for $24 \mathrm{~h}$, then supplied with 2 nd-3rd instar aphids at six different prey densities $(5,10,15,20,25$, and 35). Six replicate experiments were conducted for each aphid species and density. After $24 \mathrm{~h}$, the numbers of remaining prey were counted. 


\subsubsection{Predator Preference for Prey Species}

The Petri dish setup was as described above. To ensure that the two aphid species were of similar size, we used 1st instar nymphs of $P$. juglandis and 2nd-3rd instar nymphs of $C$. juglandicola in these experiments. Individual O. sauteri adults were starved as above, then supplied with 15 P. juglandis 1 st instar nymphs and 15 C. juglandicola 2 nd-3rd instar nymphs in one Petri dish. In this experiment, we cut the walnut leaves in half and to fit the Petri dish, a half leaf with the introduction of $P$. juglandis in the adaxial surface, and another half leaf with the introduction of $C$. juglandicola in the abaxial surface. This experiment was done in 4 in replications, with 6 Petri dishes in each replication.

\subsubsection{Biological Control Efficacy of Predatory O. sauteri against a Single Population of} P. juglandis or C. juglandicola

Three levels of $O$. sauteri density $(0,1$, and 2 adult bugs) were tested against prey aphids with each density replicated ten times. For each predator density, ten healthy walnut saplings each with six branches of the same size were selected. Five leaves at the top of each branch were used for the experiment. Ten 2nd-3rd instar C. juglandicola were placed on each of the five leaves on three branches and ten 2nd-3rd instar P. juglandis were placed on each of the five leaves of the remaining three branches per sapling. Either 0,1 , or 2 adults of $O$. sauteri were released on each branch and covered with a voile bag ( $50 \mathrm{~cm}$ long $\times 35 \mathrm{~cm}$ wide) (mesh size $0.3 \mathrm{~mm}$ ). The number of aphids remaining from the initial 50 in each voile bag was counted every 3 days and ended after 15 days.

\subsection{Field Experiments}

2.3.1. Biological Control Efficacy of Predatory O. sauteri against a Single Population of P. juglandis or C. juglandicola

Field experiments were carried out when walnut aphid populations reached peak abundance in walnut orchards located Yili County $\left(43^{\circ} 25^{\prime} \mathrm{N}, 082^{\circ} 82^{\prime} \mathrm{E}\right)$ of the Xinjiang Autonomous Region, northwestern China. During the field experiments (15 July to 29 July 2020), the daily average temperature and humidity were $23^{\circ} \mathrm{C}\left(13-33^{\circ} \mathrm{C}\right)$ and $59 \%$, respectively. No insecticide or other chemical was applied to the experimental fields. The biocontrol experiment on the single species and mixed populations were conducted simultaneously. Ten walnut trees of the same diameter trunk $(10 \mathrm{~cm})$ were randomly selected in a walnut orchard as experimental units. The experimental method was as described for the above laboratory experiments, i.e., five leaves at the end of six branches per tree had predatory bugs and prey aphids added as appropriate and covered by a voile bag.

2.3.2. Biological Control Efficacy of Predatory O. sauteri against a Mixed Population of P. juglandis and C. juglandicola

The experimental unit was similar to that in the previous experiment except that only three branches of the same size were selected on each tree and 25 P. juglandis 2nd-3rd instars and 25 C. juglandicola 2 nd-3rd instars were placed on the five leaves at the end of each branch, predators added and covered by a voile bag.

\subsection{Data Analysis}

The functional response of predatory O. sauteri bugs to increasing density of $P$. juglandis and C. juglandicola

The number of P. juglandis or C. juglandicola consumed after $24 \mathrm{~h}$ as a function of initial density was fitted to the Holling's disc equation Type II [21,22].

$$
N a=\frac{a^{\prime} N T}{1+a^{\prime} T h N}
$$

The characteristic of a Type II functional response is that predation increases at a decreasing rate with increasing prey density until a limit is reached [21]; $\mathrm{Na}$ represents the number of individual prey eaten by an individual predator per time unit, $N$ is the initial 
number of prey offered to each predator at the beginning of the experiment, $a^{\prime}$ is the rate of successful attack of prey by a predator, $T$ is the total time of the experiment, and $T h$ is the handling time.

A quadratic model was fitted to the functional response curve by non-linear least squares regression using Origin software to describe the effect of prey density on predation by an $O$. sauteri bug on the two aphid species. Predation data for each prey density were analyzed through the Kruskal-Wallis test and mean ranks were compared in pairwise comparison test at $p<0.05$ because the data did not meet the assumptions of the normal distribution by the Kolmogorov-Smirnov test [23], even after transformation.

\subsubsection{Predator Preference for Prey Species}

The preference of $O$. sauteri for one species of aphid prey over the other was estimated using the Cain Index [24]:

$$
D=\frac{N_{P_{1}} \times N_{2}}{N_{P_{2}} \times N_{1}}
$$

where $D$ is a preference index for prey, $N_{p 1}$ and $N_{p 2}$ is the number of prey 1 (P. juglandis) or prey 2 (C. juglandicola) that were eaten, $N_{1}$ and $N_{2}$ are the initial numbers of prey 1 or prey 2. $D>1$ indicates that the predator has a preference for prey 1 .

Analysis of variance (LSD) was used to compare the differences among the mean number of aphids eaten by the O. sauteri adult in the four repeated experiments for each aphid species. When there was no significant difference, data from the four repeated experiments were combined for further analysis.

2.4.2. Biological Control Efficacy of Predatory O. sauteri against P. juglandis and C. juglandicola

Three methods were used to evaluate the biological control efficacy of predatory $O$. sauteri bugs against $P$. juglandis and C. juglandicola. Firstly, control efficacy (percent control) was calculated by using the following equation [25]:

$$
\text { Control efficacy }=\left(1-\frac{N_{1}}{N_{2}}\right) \times 100 \%
$$

In Equation (3), $N_{1}$ is the number of aphids in the treated group and $N_{2}$ is the number of aphids in the untreated group at the end of the experiment.

Secondly, we used insect-days as an index of the efficacy of the predator. Cumulative insect-days were calculated by sequentially summing the individual insect-days. The insect-days formula for the area under this curve [26] was:

$$
\text { Insect }- \text { days }=\left(X_{i+1}-X_{i}\right)\left(\frac{Y_{i}+Y_{i+1}}{2}\right)
$$

where $X_{i}$ and $X_{i+1}$ are adjacent points of time, and $Y_{i}$ and $Y_{i+1}$ are the corresponding numbers of insects at those points in time. The percent reductions in cumulative insectdays indicate the percentage reduction between the treated and untreated groups.

Thirdly, we assumed that the growth of the aphid population was exponential within a limited window for the duration of the experiment. Population growth rate (PGR) was calculated using the following equation [27]:

$$
P G R=\frac{\ln \left(N_{t}\right)-\ln \left(N_{0}\right)}{\Delta t}
$$

$N_{t}$ is the number of aphids at the end of the experiment, $N_{0}$ is the number of aphids at the beginning of the experiment, $\Delta t$ is the duration of the experiment (15 days), and $\ln$ is the natural logarithm.

In all statistical analyses, the data obtained from experimental groups were processed in SPSS 19. Most data of control efficacy, percent reduction in cumulative insect-days, and 
population growth rate (PGR) obtained from our experiments did not meet the assumptions of a normal distribution using the Kolmogorov-Smirnov test, even after transformation. Thus, the data from the experiments using different densities of predators $(0,1$, or 2$)$ were compared by analysis of variance using the Kruskal-Wallis test with a $p=0.05$ level of significance.

\section{Results}

3.1. The Functional Response of Predatory O. sauteri Bugs to Increasing Density of P. juglandis and C. juglandicola

The number of prey consumed by the predatory bug increased with an increase in prey density. Overall, O. sauteri adults consumed more 2nd-3rd instars of $C$. juglandicola than of $P$. juglandis at each density. There was a significant difference in the number of C. juglandicola consumed when prey density was 5 or 10 per leaf compared to when prey density was 35 per leaf. For $P$. juglandis, there was a significant difference in the number of prey consumed at prey densities of 5 or 10 per leaf compared to 25 prey per leaf (Table 1 ).

Table 1. Mean number of 2nd-3rd instar of Panaphis juglandis and Chromaphis juglandicola aphids preyed on by an Orius sauteri adult bug on walnut leaf disks over $24 \mathrm{~h}$ at $25 \pm 2{ }^{\circ} \mathrm{C}$.

\begin{tabular}{ccccccc}
\hline \multirow{2}{*}{ Prey } & \multicolumn{5}{c}{ Prey Density (Aphids/Leaf Disc) } \\
\cline { 2 - 6 } & $\mathbf{5}$ & $\mathbf{1 0}$ & $\mathbf{1 5}$ & $\mathbf{2 0}$ & $\mathbf{2 5}$ \\
\hline Chromaphis juglandicola & $4.2 \pm 0.7^{\mathrm{bc}}$ & $4.8 \pm 1.3^{\mathrm{b}}$ & $6.2 \pm 1.1^{\mathrm{ab}}$ & $9.0 \pm 1.1^{\mathrm{ab}}$ & $11.5 \pm 0.7^{\mathrm{ab}}$ & $11.7 \pm 2.2^{\mathrm{a}}$ \\
\hline Panaphis juglandis & $3.8 \pm 0.3^{\mathrm{c}}$ & $4.0 \pm 0.3^{\mathrm{c}}$ & $6.5 \pm 1.3^{\mathrm{abc}}$ & $8.5 \pm 1.3^{\mathrm{abc}}$ & $8.8 \pm 0.5^{\mathrm{ab}}$ & $9.2 \pm 1.6^{\mathrm{abc}}$ \\
\hline
\end{tabular}

Note: Different lowercase letters indicate significant differences at the level of $p<0.05$.

The functional response of predatory O. sauteri towards C. juglandicola and P. juglandis fitted the Type II response modeled by the Holling's disc equation from the quadratic models fitted to the functional response curves by non-linear least squares regression $\left(R^{2}=0.82\right.$ and $R^{2}=0.78$, respectively). When the prey was $C$. juglandicola, the handling time (Th) was $1.73 \mathrm{~h}$, the rate of successful attack $\left(a^{\prime}\right)$ was 1.06 , and the theoretical maximum predation was 14 aphid nymphs over $24 \mathrm{~h}$. When the prey was the larger $P$. juglandis, the $T h$ was $2.01 \mathrm{~h}, a^{\prime}$ was 1.01 , and the theoretical maximum predation rate was 12 aphid nymphs over $24 \mathrm{~h}$.

\subsection{Predator Preference for Prey Species}

The number of $P$. juglandis and $C$. juglandicola eaten by the adult $O$. sauteri was not significantly different among the four repetitions of the experiment $(F=1.75, d f=3, p>0.05$ for $P$. juglandis; $F=2.17, d f=3, p>0.05$ for $C$. juglandicola), so data were pooled. More $P$. juglandis nymphs than $C$. juglandicola nymphs were eaten by O. sauteri. The Cain Index (D) was more than 1 indicating that O. sauteri preferred P. juglandis (Table 2).

Table 2. Prey choice of predatory O. sauteri bug against two walnut aphid species.

\begin{tabular}{ccccc}
\hline \multicolumn{2}{c}{$\boldsymbol{P}$. juglandis } & \multicolumn{2}{c}{ C. juglandicola } & \multirow{2}{*}{ Cain Index } \\
\cline { 1 - 4 } Density & Predation $\left(\boldsymbol{N}_{\boldsymbol{p} \mathbf{1}}\right)$ & Density & Predation $\left(\boldsymbol{N}_{\boldsymbol{p} \mathbf{2}}\right)$ & \\
\hline 15 & $6.87 \pm 0.47$ & 15 & $4.25 \pm 0.51$ & $1.82 \pm 0.22$ \\
\hline
\end{tabular}

3.3. Biological Control Efficacy of Predatory O. sauteri against a Single Population of P. juglandis or C. juglandicola in the Laboratory and Field

In both laboratory and field experiments, O. sauteri effectively controlled populations of each aphid species. In the untreated groups in the laboratory and field, the populations of $P$. juglandis began to increase rapidly on the ninth day, but after 15 days the population size in the laboratory was less than in the field populations ( $27 \pm 50$ versus $486 \pm 65$, respectively). The laboratory populations of $C$. juglandicola began to increase rapidly on 
the sixth day, but the field populations began to reproduce on the third day; after 15 days, the mean number of aphids in the laboratory populations was greater than in the field populations (1610 \pm 227 versus $534 \pm 39$, respectively) (Figure 1).

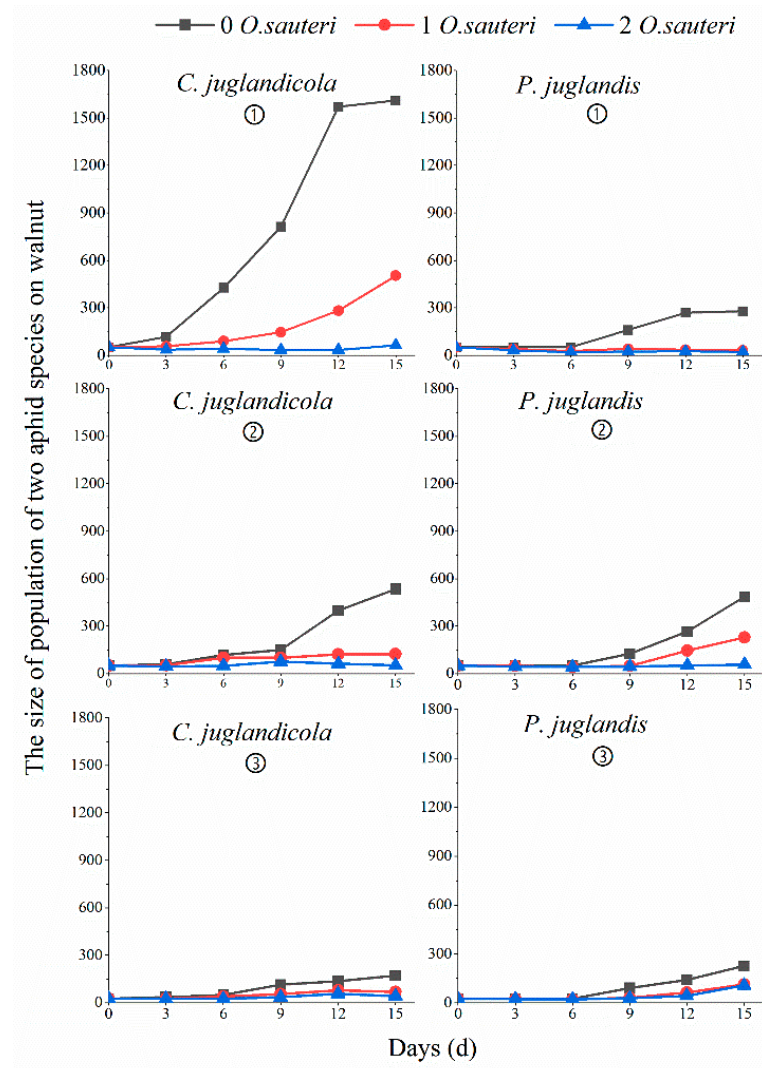

Figure 1. The mean number of aphids in populations of two aphid species exposed to an initial density of 0,1 , and 2 O. sauteri predatory bugs over 15 days. Note: (1) indicates the laboratory experiments, (2) indicates the field experiments, (3) indicates the mix population experiments.

The populations of $P$. juglandis, as well as $C$. juglandicola, declined after 15 days if treated with predators. The mean control efficacy of $P$. juglandis were $79 \% \pm 8.7 \%$ with 1 predator and $92 \% \pm 4.3 \%$ with 2 predators in the laboratory while in the field the means were $54 \% \pm 8.7 \%$ and $84 \% \pm 6.1 \%$ with 1 or 2 predators. In the case of $C$. juglandicola, the mean control efficacy was $63 \% \pm 13.2 \%$ and $95 \% \pm 4.6 \%$ with 1 or 2 predators in the laboratory but in the field, the means were $76 \% \pm 6.1 \%$ and $90 \% \pm 2.3 \%$ with 1 or 2 predators. The mean control efficacy of $O$. sauteri was highest by using these two predator densities $(p<0.05)$. The percent reduction of cumulative insect-days of populations with predatory bugs compared to control populations with no predatory bug(s) also indicated that $O$. sauteri suppressed the population size of $P$. juglandis and $C$. juglandicola. The mean percent reduction of $P$. juglandis and $C$. juglandicola were greater in the laboratory experiments than in the field experiments (P. juglandis: $p<0.05 ; C$. juglandicola: $p<0.05)$. In the laboratory, $P$. juglandis exhibited a mean percent reduction of cumulative insect-days which were $67 \% \pm 6.2 \%$ and $78 \% \pm 4.9 \%$ with 1 or 2 predators. The mean percent reduction of cumulative insect-days of $C$. juglandicola were $70 \% \pm 9.7 \%$ and $93 \% \pm 3.3 \%$ with 1 or 2 predators. Field experiments revealed that the mean of P. juglandis were $44 \% \pm 5.5 \%$ and $66 \% \pm 4.6 \%$ with 1 or 2 predators but for C. juglandicola the mean was $54 \% \pm 7.3 \%$ and $71 \% \pm 4.4 \%$ with 1 or 2 predators. Two adult $O$. sauteri were more effective than one adult O. sauteri. $(p<0.05)$ (Figure 2$)$. 


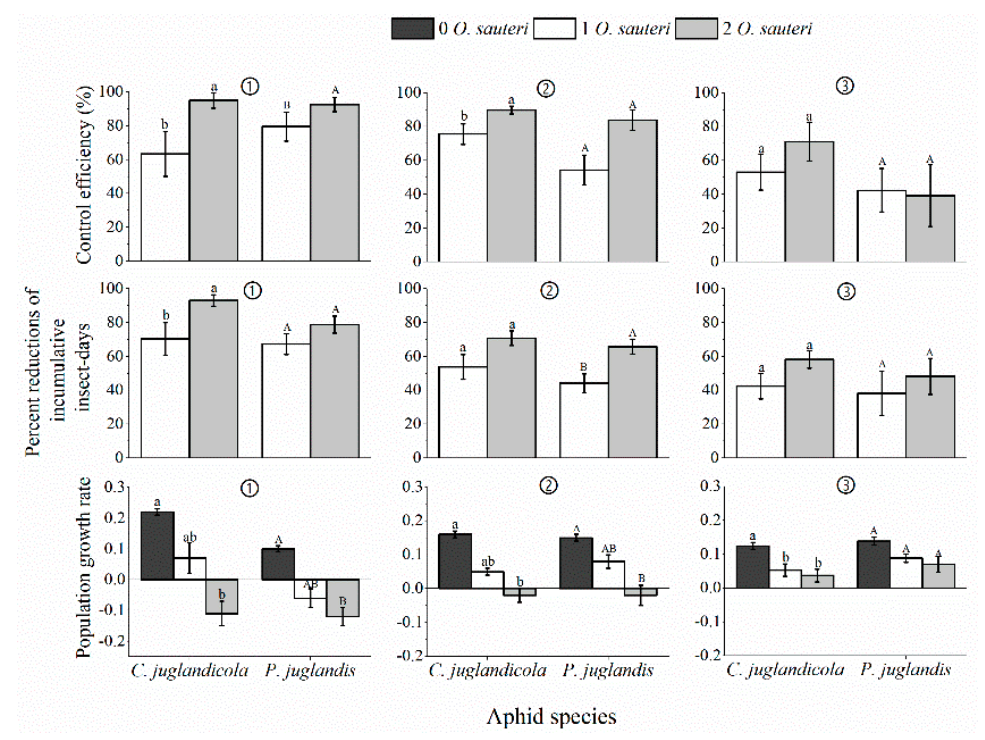

Figure 2. The control efficacy, percent reduction of cumulative insect-days, and population growth rate of two aphid species exposed to an initial density of 0,1 , and 2 O. sauteri predatory bugs over 15 days. Note: Different lowercase letters a and $\mathrm{b}$ indicate significant differences at the level of $p<0.05$ for C. juglandicola; different capital letters A and B indicate significant differences at the level of $p<0.05$ for P. juglandis; (1) indicates the laboratory experiments, (2) indicates the field experiments, (3) indicates mix population experiments.

The mean population growth rates (PGR) of $P$. juglandis were $0.1 \pm 0.01,-0.06 \pm 0.03$, and $-0.12 \pm 0.03$ with 0,1 , or 2 predators in the laboratory, while in the field they were $0.15 \pm 0.01,0.08 \pm 0.02$, and $-0.03 \pm 0.03$ with 0,1 , or 2 predators. In the case of $C$. juglandicola, the mean growth rates were $0.22 \pm 0.01,0.07 \pm 0.05$, and $-0.11 \pm 0.03$ with 0,1 , or 2 predators in the laboratory, and in the field, the mean were $0.16 \pm 0.01,0.05 \pm 0.01$, and $-0.02 \pm 0.02$ with 0,1 , or 2 predators. The mean population growth rates (PGR) were significantly different in the presence and absence of different initial densities of $O$. sauteri bugs $(H=19.1, d f=2, p<0.05$ for $P$. juglandis in the laboratory; $H=18.1, d f=2, p<0.05$ for $C$. juglandicola in the laboratory; $H=18.2, d f=2, p<0.05$ for $P$. juglandis in the field; $H=21.4, d f=2, p<0.05$ for $P$. juglandis in the field). Aphid populations treated with two adult $O$. sauteri had lower PGRs than those treated with one. The PGR of $P$. juglandis populations $(-0.12 \pm 0.03)$ was less than $C$. juglandicola $(-0.11 \pm 0.03)$ in laboratory experiments. Conversely, the PGR of the $P$. juglandis population $(-0.03 \pm 0.02)$ was greater than $C$. juglandicola $(-0.02 \pm 0.02)$ treated with two predatory bugs in field experiments (Figure 2).

3.4. Biological Control Efficacy of Predatory O. sauteri against a Mixed Population of P. juglandis and C. juglandicola Aphids in the Open Field

Overall, exposure of a mixed population of P. juglandis and C. juglandicola aphids to one or two O. sauteri predatory bugs resulted in increased control efficacy, increased percent reduction in cumulative insect-days, and decreased PGRs compared to control populations without bug(s) in a trend similar to experiments using single-species populations in the field (Figure 2). Releasing two O. sauteri resulted in better control than using one. However, the bio-control efficacy of one and two predatory bug(s) against $P$. juglandis and C. juglandicola aphids in a mixed population was different for the two species over time (Figure 1). After 15 days exposed to two predatory bugs, the mean population of $P$. juglandis was $107 \pm 22$, higher than the mean number of $41 \pm 8$ per $C$. juglandicola population. The control efficacy and the percent reduction in cumulative insect-days resulting from exposure of a mixed population of the two aphid species to one or two predatory O. sauteri bugs were lower than for the same species of aphid in a single population (Figure 2). In addition, the mean PGRs of the two aphid species in mixed populations were higher than for the 
two species in single populations when exposed to one or two predatory bugs. In the treatments with two O. sauteri against a mixed aphid population, the control efficacy of C. juglandicola was significantly higher $(71 \% \pm 11.5 \%)$ than when one $O$. sauteri was released $(39 \% \pm 18.3 \%)$. The control efficiency of P. juglandis was similar for one $(42 \% \pm 12.8 \%)$ and two $(39 \% \pm 18.3 \%)$ predator treatments as well.

\section{Discussion}

Our experiments revealed that $O$. sauteri adults were effective in suppressing populations of the two walnut aphids P. juglandis and C. juglandicola. Functional responses showed the predator had a strong capacity for consuming aphids of the two species in both laboratory and open field experiments.

The control efficacy of $O$. sauteri against $P$. juglandis and C. juglandicola aphids was greater than has been found against other aphid pests. Under laboratory conditions, the theoretical predation capacity of 4-5th instar O. sauteri on Aphis glycine (Matsumura) was up to 8 per day [28], and on Brevicoryne brassicae (Linnaeus) adults it was 6 per day [29]. We found that $O$. sauteri consumed approximately 12 P. juglandis or 14 C. juglandicola 2 nd-3rd instar aphids within $24 \mathrm{~h}$. Furthermore, the two aphid species were quite different in size (e.g., the 2nd-3rd instar of P. juglandis was larger than C. juglandicola) [30]. So, although slightly more C. juglandicola were eaten, the biomass of $P$. juglandis consumed was greater.

Comparing the biological control efficacy of predatory O. sauteri against populations of a single species of walnut aphid, the decline in aphid numbers was greater in laboratory experiments than in open field experiments suggesting environmental factors can influence efficacy; abiotic variables can affect predation of predatory bug populations, such as the change in temperature, humidity, wind, and rain. [31,32]. The laboratory conditions with stable climate led to consumption increasing by predators [33]. By contrast, during our field study, the highest temperature was $33{ }^{\circ} \mathrm{C}$ at noon and the lowest was $14{ }^{\circ} \mathrm{C}$ at night, predatory capacity can be negatively affected by extreme temperature [34], and the temperature fluctuation in the field also influenced the population dynamics of predators [35]. In addition, wind interfering with the movement and sensing of olfactory cues might affect predator feeding performance and ultimately cause a decline in the biocontrol efficacy [36].

Biotic factors, including prey insects, can determine the biocontrol efficacy of predators. P. juglandis was consumed more often by O. sauteri than C. juglandicola when both were provided in laboratory prey choice experiments. However, the effect of this preference for P. juglandis over C. juglandicola was not always reflected in our field experiments. For example, when mixed populations of aphids (equal numbers of both species) were exposed to O. sauteri, the number of P. juglandis was greater than the numbers of C. juglandicola in the populations after 15 days. The preferred orientation of aphids on their host tree due to insect phototaxis may explain this result. Both the predatory bug O. sauteri and C. juglandicola aphids prefer to inhabit the lower surface of walnut tree leaves thus increasing the likelihood of encounters between the two. Orius sauteri are sensitive to light and distribute on the lower surface of leaves [37]. Conversely, P. juglandis aphids are found on the adaxial surface of leaves and are less likely to come into contact with O. sauteri.

The density of aphid prey affected the biocontrol of predators in our study. The number of aphids consumed by the predatory bug in one day increased with increasing prey density, as has been found for other predatory bugs: Xylocoris flavipes (Reuter) against the beetles Tribolium castaneum (Herbst) and Attagenus megatoma (F.) [38], as well as Macrolophus pygmaeus (Rambur) against Myzus persicae (Sulzer) [39,40]. The biocontrol efficacy of O. sauteri against each aphid species in a mixed-species population was less than in a single-species population. Population size dropped significantly when two species were mixed on the same leaf compared with single populations of each aphid species. Studies have shown competition for food and space between C. juglandicola and P. juglandis [41], in mixed-species aphid populations, there may be competition among individuals of the two aphid species leading to a decline of population size compared to single-species populations. Biocontrol efficacy of $O$. sauteri declined in the mixed group due to the lower 
density, with lower prey capacity determined by the competition among two coexisting aphids in our study.

All three approaches to measuring changes in aphid prey population used in our study described the biological control efficacy of $O$. sauteri bugs well. Control efficacy, in a classic approach, focuses on the final number of aphids exposed to the predator relative to the predator-free group regardless of the timing. However, the cumulative insect-days served as an index of the overall effectiveness of the predator; the integrated area under the curve of insect numbers over time described the biological control function or effectiveness of the predator. Both the abundance of pest aphids remaining, and infestation duration (timing) were considered [28]. In addition, the PGR of aphids can be used as an indicator of the efficacy of a biological control agent. The initial and final abundance of aphids and the time interval were used for the calculation of PGR (see Equation (5)). The lower the PGR the higher the bio-control efficacy (negative values of PGR are best) and the greater the reduction of insect-days. The combination of these three approaches should be considered when assessing bio-control practices.

This is the first report of the biocontrol of O. sauteri on two walnut aphid species based on both laboratory and field experiments. Further studies are needed to evaluate the control efficacy of $O$. sauteri in the context of a practical economic threshold for aphid infestation in orchard situations.

\section{Conclusions}

Orius sauteri can be a potential biological control agent for P. juglandis and C. juglandicola in walnut orchards. The functional response reflects the high consumption of the predator against two aphid species. The predator's prey preference indicated $P$. juglandis was preferred, nevertheless, it was more effective in controlling C. juglandicola in the mixed aphid populations in the field. Control efficacy against single populations of the two aphid species was higher in laboratory experiments than in the open field. In the open field experiments, efficacy declined in mixed populations compared to single populations, particularly for the larger walnut aphid ( $P$. juglandis) due to behavioral differences and competition between the two aphid species. Successful control may require higher release rates when both species are present.

Author Contributions: Z.L.: Conceptualization, Methodology; T.W. and M.P.Z.: collecting data and writing; P.Z. and C.M.: statistics; M.Y.A.: writing, review and editing; G.G.: review \& editing. All authors have read and agreed to the published version of the manuscript.

Funding: The work was supported by the National Natural Science Foundation of China (31670656, 31960317).

Institutional Review Board Statement: Not applicable for studies not involving humans or animals. Informed Consent Statement: Not applicable for studies not involving humans.

Data Availability Statement: There is no additional data to disclose, all data are included in this manuscript.

Acknowledgments: We thank Ma Huailiang for field study support collecting and counting aphids.

Conflicts of Interest: The authors declare no conflict of interest.

\section{References}

1. Orre-Gordon, G.U.S.; Wratten, S.D.; Tompkins, J.M.; Jonsson, M.; Jacometti, M.A. Provision of floral resources for biological control: Restoring an important ecosystem service. Funct. Ecosyst. Communities 2007, 1, 86-94.

2. O'Neil, R.J.; Giles, K.L.; Obrycki, J.J.; Mahr, D.L.; Legaspi, J.C.; Katovich, K. Evaluation of the Quality of Four Commercially Available Natural Enemies. Biol. Control 1998, 11, 1-8. [CrossRef]

3. van Lenteren, J.C. Ecosystem services to biological control of pests: Why are they ignored? Proc. Neth. Entomol. Soc. Meet. 2006, $17,103-111$.

4. Costanza, R.; d'Arge, R.; de Groot, R.; Farber, S.; Grassot, M.; Hannon, B.; Limburg, K.; Naeem, S.; O’Neill, R.V.; Paruelo, J.; et al. The value of the world's ecosystem services and natural capital. Nature 1997, 387, 253-260. [CrossRef]

5. van Lenteren, J.C. IOBC Internet Book of Biological Control. IOBC-Global 2012, 6, 182. 
6. KrzyŻAnowski, R. Population dynamics and spatial distribution of Panaphis juglandis (Goeze, 1778) (Hemiptera: Aphididae) on common walnut (Juglans regia L.). Folia Pomer. Univ. Technol. Stetin. Agric. Aliment. Pisc. Zootech. 2018, 341, 29-40. [CrossRef]

7. Aqaverdi, N.I.; Inqilab, N.G. Some bioecological pecularities of panaphis juglandis (Goeze, 1778) and chromaphis juglandicola (Kaltenbach, 1843) (Hemiptera, Aphididae) the pests of Persian walnut (Juglans regia L.) in Azerbaijan. J. Entomol. Zool. Stud. 2018, 6, 800-803.

8. Steinmann, K.P.; Zhang, M.; Grant, J.A.; Pickel, C.; Goodhue, R.E. Pheromone-based pest management can be cost-effective for walnut growers. Calif. Agric. 2008, 62, 105-110. [CrossRef]

9. Akkopru, E.P.; Han, R.A.; Okut, H.; Chi, H. Demographic assessment of plant cultivar resistance to insect pests: A case study of the dusky-veined walnut aphid (Hemiptera: Callaphididae) on five walnut cultivars. J. Econ. Entomol. 2015, 108, 378-387. [CrossRef]

10. Wani, S.; Ahmad, S. Biology and population dynamics of new colour morph of Chromaphis juglandicola Kalt. J. Entomol. Zool. Stud. 2015, 3, 28-31.

11. Jaskiewicz, B.; Kmiec, K. The occurrence of Panaphis juglandis (Goetze) and Chromaphis juglandicola (Kalt.) on walnut under the urban conditions of Lublin. Acta Sci. Pol. Hortorum Cultus 2007, 6, 15-26.

12. van den Bosch, R.; Frazer, B.D.; Davis, C.S.; Messenger P.S.; Hom, R. Trioxys pallidus an effective walnut aphid parasite from Iran. Calif. Agric. 1970, 24, 8-10.

13. Singh, R.; Singh, G. Chapter 3: Aphids and their biocontrol. In Ecofriendly Pest Management for Food and Security; Academic Press: Cambridge, MA, USA, 2016; pp. 63-108.

14. Letourneau, D.K.; Altierl, M.A. Abundance patterns of a predator, Orius tristicolor (Hemiptera: Anthocoridae), and its prey, Frankliniella occidentalis (Tysanoptera Thripidae) habitat attraction in polycultures versus monocultures. Environ. Entomol. 1983, 12, 1464-1469. [CrossRef]

15. Isenhour, D.J.; Yeargan, K.V. Predation by orius insidiosus on the soybean thrips, sericothrips variabilis: Effect of prey stage and density. Environ. Entomol. 1981, 10, 496-500. [CrossRef]

16. Isenhour, D.J.; Yeargan, K.V. Interactive behavior of Orius insidiosus [Hem.: Anthocoridae] and Sericothrips variabilis [Thys.: Thripidae]: Predator searching strategies and prey escape tactics. Entomophaga 1981, 26, 213-220. [CrossRef]

17. Wang, Y.P.; Wu, H.; Bu, W.J.; Xu, H.C. Geographic distribution of the genus Orius Wolff (Heteroptera: Anthocoridae). J. Zhejiang For. Coll. 2003, 20, 389-393.

18. Nagai, K.; Yano, E. Predation by Orius sauteri (Poppius) (Heteroptera: Anthocoridae) on Thrips palmi Karny (Thysanoptera: Thripidae): Functional response and selective predation. Appl. Entomol. Zool. 2000, 35, 565-574. [CrossRef]

19. Paik, C.H.; Lee, G.H.; Hwang, C.Y.; Kim, S.J. Predatory Response of the Pirate Bug, Orius sauteri Poppius (Heteroptera: Anthocoridae) on Frankliniella occidentalis, Aphid gossypii and Tetranychus urticae. Korean J. Appl. Entomol. 2010, 49, 401-407. [CrossRef]

20. Ogino, T.; Yamaguchi, T.; Uehara, T.; Kainoh, Y.; Shimoda, M. Analysis of the activity rhythm of the predatory bug Orius sauteri (Poppius) (Heteroptera: Anthocoridae) for optimizing its selective light attraction. Appl. Entomol. Zool. 2019, 55, 115-120. [CrossRef]

21. Holling, C.S. Some characteristics of simple types of predation and parasitism. Can. Entomol. 1959, 7, 385-398. [CrossRef]

22. Jeschke, J.M.; Tollrian, K.R. Predator functional responses: Discriminaing between handling and digesting pery. Ecol. Monogr. 2002, 72, 95-112. [CrossRef]

23. Chakravarti, I.M.; Laha, G.A.; Roy, J. Handbook of Methods of Applied Statistics; John Wiley and Sons: Hoboken, NJ, USA, 1967; Volume 1, pp. 392-394.

24. Mei, Z.J.; Lu, Y.j.; Li, J.Y.; Wang, Z.Y.; Zheng, M.; Wang, Y. Predation functional response and preference of several the third instar s, torage pests by Xylocoris flavipes. J. Chin. Cereals Oils Assoc. 2019, 34, 104-109.

25. Jabra-Rizk, M.A.; Shirtliff, M.; James, C.; Meiller, T. Effect of farnesol on Candida dubliniensis biofilm formation and fluconazole resistance. FEMS Yeast Res. 2006, 6, 1063-1073. [CrossRef] [PubMed]

26. Ruppel, R.F. Cumulative insect-days as an index of crop protectionl. J. Econ. Entomol 1983, 76, 375-377. [CrossRef]

27. Chen, X.D.; Stark, J.D. Individual- and population-level toxicity of the insecticide, spirotetramat and the agricultural adjuvant, Destiny to the Cladoceran, Ceriodaphnia dubia. Ecotoxicology 2010, 19, 1124-1129. [CrossRef] [PubMed]

28. Han, L.L.; Dong, T.Y.; Zhao, K.J.; Zhu, M.; Sun, W.P.; Xu, Z.X.; Shi, L. Predation of Aphis glycines by Orius sauteri nymphs. Chin. J. Biol. Control 2015, 31, 322-326.

29. Wu, Y.Q.; Zhao, M.Q.; Yang, S.F.; Duan, Y.; Jiang, Y.L. Predations of Orius sauteri (Hemiptera: Anthocoridae) on four insect pests. Chin. J. Biol. Control 2010, 26, 13-17.

30. Yerim, L.; Sora, K.; Seunghwan, L. A first record of three aphid pests (Aphididae: Calaphidinae) on walnut in Korea. J. Asia-Pac. Biodivers. 2018, 11, 531-537.

31. Abbasi, Z.; Sultana, R.; Wagan, M.S. Impact of abiotic factors on population fluctuation of aphid (Hemiptera: Aphididae) on the different wheat varieties from Larkana district. J. Entomol. Zool. Stud. 2019, 7, 608-611.

32. Karczmarz, K. Numerical strength dynamics of Chromaphis juglandicola (Kalt. 1843) on common walnut (Juglans regia L.) in Lublin town plantings. Acta Sci. Pol. Hortorum Cultus 2010, 9, 121-132.

33. Romero, G.Q.; Gonçalves-Souza, T.; Kratina, P.; Marion, N.A.C.; Petry, W.K.; Sobral-Souza, T.; Roslin, T. Global predation pressure redistribution under future climate change. Nat. Clim. Chang. 2018, 8, 1087-1091. [CrossRef] 
34. Lin, Q.C.; Chen, H.; Yin, Y.Y.; Zhang, S.C.; Yu, Y.; Zhuang, Q.Y.; Zheng, L.; Zhai, Y.F. Effects of temperature on the development and predation of Aphidoletes aphidimyza (Rondani) larvae. Chin. Appl. Entomol. 2019, 56, 79-84.

35. Bretagnolle, V.; Gallis, H. Chapter 15: Predator-prey interactions and climate change. In Effects of Climate Change on Birds; Oxford University Press: Oxford, UK, 2019; pp. 119-220.

36. Barton, B.T. Reduced wind strengthens top-down control of an insect herbivore. Ecology 2014, 95, 2375-2381. [CrossRef]

37. Feng, N.; Fan, F.; Tao, B.; Yang, X.F.; Wei, G.S. Effect of spectral sensitivity response on the phototaxis of Orius sauteri (Poppius). Acta Ecol. Sin. 2015, 35, 4811-4815.

38. Lecato, G.L. Predation by Xylocoris flavipes [Hem.: Anthocoridae]: Influence of stage, species and density of prey and of starvation and density of predator. Entomophage 1976, 21, 217-221. [CrossRef]

39. Fantinou, A.A.; Perdikis, D.C.; Maselou, D.A.; Lambropoulos, P.D. Prey killing without consumption: Does Macrolophus pygmaeus show adaptive foraging behaviour? Biol. Control 2008, 47, 187-193. [CrossRef]

40. Maselou, D.A.; Perdikis, D.C.; Sabelis, M.W.; Fantinou, A.A. Use of plant resources by an omnivorous predator and the consequences for effective predation. Biol. Control 2014, 79, 92-100. [CrossRef]

41. Wani, S.A.; Ahmad, S.T. Competition and niche-partitioning in two species of walnut aphids. Int. J. Sci. Res. Rev. 2014, 3, 120-125. 